\title{
O PENSAMENTO QUEER SOBRE OS CORPOS QUE EXISTEM: e a emergência de falar em sexualidade sobre a forma de subversão a normatividade
}

\author{
Ariana Souza Cavalheiro* \\ Rodrigo Lemos Soares ${ }^{* *}$ \\ Eliane Rose Maio***
}

\begin{abstract}
Resumo: No artigo apresentamos discussões à luz dos pensamentos e contribuições do Grupo de Estudos de Educação e Relações de Gênero - GEERGE, da Universidade Federal do Rio Grande do Sul, referentes à Pedagogia Queer, sexualidades, relações de gênero e normatização presentes nos espaços escolares. Refletimos sobre uma padronização das pedagogias escolares, voltando o olhar para as crianças pequenas, às quais de alguma maneira tendem a resistir a essas normatizações hegemônicas e heteronormativas, difundidas como única e possível forma de viver e constituir as sexualidades. Buscamos compreender como ocorre a educação de meninos e meninas que subvertem essas fronteiras de padrões impostos, como estes corpos tornam-se invisíveis ao não se encaixarem na norma heterossexual. Quais as estratégias que a Pedagogia Queer oferece para tornar visíveis estes corpos, trazendo-os para ordem discursiva, do dizível.
\end{abstract}

Palavras-Chave: Educação para sexualidade, GEERGE, Pedagogia Queer.

\section{QUEER THINKING ABOUT THE BODIES THAT EXIST:}

and the emergence of talk about sexuality in the form of Subversion to normativity

\begin{abstract}
In the article we present discussions in the light of the thoughts and contributions of the study group on education and gender relations, the Federal University of Rio Grande do Sul, related to Pedagogy, Queer sexualities, gender relations and norms present in school spaces. We reflect on a standardization of school pedagogies, raising our eyes for the little kids, which somehow tend to resist these hegemonic norms and heteronormativas, broadcast as the only possible way to live and be Sexualities. We seek to understand how the education of boys and girls who subvert those standards imposed borders, as these bodies become invisible not fit on standard straight. What are the strategies that the Queer Pedagogy offers to make visible those bodies, bringing them to discursive order, the speakable. Key-words: Education for sexuality, GEERGE, Queer Pedagogy
\end{abstract}

Submissão 25-10-19 Aceite 25-10-19

\section{DANDO VISIBILIDADE AOS CONCEITOS...}

A irreverência e a disposição antinormalizadora da teoria Queer me incitam a jogar com suas ideias, sugestões, enunciados e a testá-los no campo (usualmente normalizador) da educação. Quero apostar em suas articulações, pôr em movimento o subversivo, arriscar o impensável, fazer balançar estabilidades e certezas - processos geralmente estranhos ou incômodos aos currículos, às práticas e às teorias pedagógicas (LOURO, 2013. p, 7).

\footnotetext{
* Mestre em Educação pelo Programa de Pós Graduação/PPGedu - FURG. Especialista em Educação Física Escolar pela Pós-Graduação em Educação Física escolar do Instituto de Educação - FURG. Graduada em Pedagogia Licenciatura pela Universidade Federal do Rio Grande - FURG.

** Universidade Federal de Pelotas - UFPEL/ Grupo Interdisciplinar de Pesquisa: Narrativas, Arte, Linguagem e Subjetividade (GIPNALS)

**** Possui graduação em Psicologia pela Universidade Estadual de Maringá (1984), Mestrado em Psicologia pela Universidade Estadual Paulista - UNESP/Assis (2002), Doutorado em Educação Escolar - UNESP/Araraquara (2008), Pós-doutorado em Educação Escolar na UNESP/Araraquara, com a temática da Trajetória da Educação Sexual no Brasil. É professora da Universidade Estadual de Maringá, no Departamento de Teoria e Prática da Educação. Atua como comitê Ad hoc da ANPEd, do GT-23 - Gênero, Sexualidade e Educação. É líder do grupo de pesquisa CNPq, intitulado Núcleo de Pesquisa e Estudo em Diversidade Sexual - NUDISEX.
} 
Para apresentar as discussões desta escrita, nos despimos de quaisquer pressupostos que unifiquem ou normatizem os sujeitos. Lançamos mão do que está estabelecido no contexto escolar, e nos permitimos a repensar em uma educação antinormalizadora.

Muitos de vocês leitores/as os/as quais não estão inseridos/as neste contexto de discussão acerca da sexualidade e de padrões normativos, devem estar se perguntando; mas o que é essa educação antinormalizadora? Pois bem!

É exatamente o que nos debruçamos a problematizar nessa discussão. O que é normalizar, padronizar, definir como único, dispor meios e estratégias de caracterizar um modelo a ser estabelecido a todos os corpos que de um determinado meio. Pensar no que não se encaixa, que está fora, que incomoda, que é estranho, que não está enquadrado nesse padrão normalizador, está caracterizado como subversivo, ou seja, passam a tornam-se corpos queer.

Miskolci (2013), assume uma discussão de que esse corpo é um constructo de um reconhecimento sem assimilação, sem comparação ao/à outro/a, por vez, é fruto de resistência à algo que está sendo culturalmente imposto. Entretanto, ressalta que escola deve trabalhar a partir dessa resistência com a 'anormalidade', ou seja, "ao invés de punir, vigiar ou enquadrá-los, romper com essa estranheza e ressignificar esse processo de aprendizagem do estranho/anormal" (MISKOLCI, 2013, p. 67).

Neste viés, os corpos caracterizados por comportamentos não aceitos pela sociedade, passam a tornar-se invisíveis, pois não considerados 'normais', não podem servir de modelo para outros sujeitos em construção. A escola ainda não assumiu um caráter de reconhecimento do sujeito queer, o sujeito constituído a partir de seu desejo pessoal. Assim esse processo reflete dentro do ambiente escolar, fundamentado pela educação proposta pelos/as professores/as, que muitas vezes passam a não considerar estes outros corpos que existem.

Mesmo que existam regras, que se tracem planos e sejam criadas estratégias e técnicas, haverá aqueles e aquelas que rompem as regras e transgridem os arranjos. [...] esses se tornarão, estão, os alvos preferenciais das pedagogias corretivas e das ações de recuperação ou de punição. Para eles e para elas a sociedade reservará penalidades, sanções, reformas e exclusões (LOURO, 2013. p, 16).

Neste contexto, evidenciamos que tais reflexões acerca das relações de gênero, sexualidades e questões sociais, ganharam espaços de discussão, 
a partir das problematizações e interlocuções da Prof ${ }^{a}$ Guacira Lopes Louro ${ }^{1}$, a qual, juntamente com um grupo de estudantes de pós-graduação, fundou em 1990 o GEERGE - Grupo de Estudos de Educação e Relações de Gênero da Universidade Federal do Rio Grande do Sul - UFRGS. Passando a dar visibilidade e potencializando as esferas relacionadas aos gêneros, sexualidades, etnia e educação.

Sendo este o grupo mais antigo do Brasil, tendo seu reconhecimento pelo CNPq - Conselho Nacional de Desenvolvimento Científico e Tecnológico, como uma instância acadêmica a qual se destina a formar pesquisadores/as, tocados/as pela ação do investigar e pensar sobre educação, sexualidade e as relações de gênero. Tornam-se uma fundamental referência no campo dos estudos de gênero, sexualidade e educação.

Neste viés, para dialogarmos sobre tal invisibilidade dos corpos queer, e os padrões normativos que se instituem ainda hoje em nossa sociedade, trazemos como reflexão o espaço escolar, o qual ainda hoje, se mantém arraigado pelos padrões que impõem tais comportamentos e institui normas de constituição e ressignificação dos corpos. Deixando à margem aqueles/as os/as quais, transgredir esse padrão. Segundo Louro (2013, p. 15), tais modos ainda são estabelecidos pela própria sociedade, pois

constroem os contornos demarcadores das fronteiras entre aqueles que representam a norma (que estão em consonância com seus padrões culturais) e aqueles que ficam fora dela, às margens. Em nossa sociedade, a norma que se estabelece, historicamente, remete ao homem branco, heterossexual, de classe média urbana e cristão, e essa passa a ser a referência que não precisa ser nomeada.

Sendo assim, as classificações e os rótulos, passam a demarcar os indivíduos, com a pretensão de instituir identidades e definir o que cabe ao gênero feminino e masculino, rejeitando pensar em outra possibilidade que não seja enquadrada nessa referência padronizada. Assim, "uma matriz heterossexual delimita os padrões a serem seguidos e, ao mesmo tempo, paradoxalmente, fornece a pauta para as transgressões" (LOURO, 2013. p, 17). Os corpos que transgridem a essa normatividade tornam-se invisíveis, seus sentimentos, suas atitudes, seus atos, seus comportamentos, são velados e muitas vezes negados, para que outros corpos não o tomem como modelo.

Assim como diz a epígrafe que inicia esta escrita, por motivos de indiferença e por não corresponderem às expectativas desejadas. Meninos que brincam de boneca

\footnotetext{
${ }^{1}$ Graduada em História e Mestre em Educação pela Universidade Federal do Rio Grande do Sul - UFRGS. Doutora em Educação pela UNICAMP. Professora de Pós-graduação da UFRGS. Em 2012 Guacira Louro recebeu o prêmio Paulo Freire, concedido durante a $35^{\mathrm{a}}$ Reunião Anual da Associação Nacional de Pós-Graduação e Pesquisa em Educação (ANPEd), que ocorreu em Porto de Galinhas-PE. Tem no currículo diversos livros publicados, assim como artigos e capítulos que em sua maioria tratam de questões de gênero, sexualidade e Estudos Queer. Disponível em: https://www.ufrgs.br/geerge/
} 
e meninas que brincam de carrinho, são atos e atitudes negadas pelo/a professor/a na escola, pois não é 'aceitável' meninos e meninas brincarem com esse tipo de brinquedos.

É possível refletir sobre as palavras de Felipe (2013, p.40), onde nos explica que:

fixar uma determinada identidade como norma é uma das formas privilegiadas de hierarquização das identidades e das diferenças [...] Normalizar significa eleger - arbitrariamente - uma identidade específica como o parâmetro em relação ao qual as outras identidades são avaliadas e hierarquizadas. Normalizar significa atribuir a essa identidade todas as características positivas possíveis, em relação ás quais as outras identidades só podem ser avaliadas de forma negativa. [...] A força da identidade normal é tal que ela nem sequer é vista com "uma" identidade, mas simplesmente como "a" identidade.

Assim a escola ainda mantém atitudes heteronormativas para os gêneros. Cabe pensar sobre o entendimento que as crianças já estabeleceram sobre seu gênero e sexualidade, oportunizando-lhes a pensar sobre as diversidades que constituem o ambiente, no qual, relacionam entre si. Camargo (1999, p. 43), ressalta que, "a escola é encarregada de transmitir cultura e formas de comportamento aceitas pela sociedade, mas pode também ser um espaço de questionamento desses comportamentos". Entretanto mantém práticas de resistências que não se sensibilizam a promover tais problematizações, reproduzindo assim a reprodução das atitudes heteronormativas.

Berenice Bento (2011) propõe uma reflexão a partir de seu entendimento de que esses processos nada mais são, do que, uma engenharia de produção de corpos 'normais'. Ressaltando que a sociedade produz padrões normativos, instituídos como únicos sobre o que deve ser reproduzido, quais os comportamentos são permitidos, quais os comportamentos são negados. Discute ainda, que a instituição escolar provida de poder, pode e deve extrapolar esses muros que demarcam tais engenharias, e abrir mão do espaço de invisibilidade e silenciamento desses/as outros/as.

Quando falamos nestes/as 'outros/as', pensamos que a diferença é algo que não existe em nós, mas ela existe, e foi normalizada, apagada ou ignorada. "A educação, infelizmente, até hoje constitui um conjunto de técnicas que faz o/a outro/a ser do jeito que a gente quer" (MISKOLCI, 2001. p, 53). Neste segmento, a instituição escolar arraigada pelas engenharias e dessensibilizada pelas diferenças, passa a ensinar o professor como ensinar a ser normal. Pensando sobre a proposta do queer, Miskolci (2011, p. 40) ressalta que 
[...] é muito mais fazer um diálogo com aqueles e aquelas que normalmente são desqualificados do processo educacional e também do resto da experiência de vida na sociedade, e é esse diálogo que pode se tornar a própria educação, mudando o papel da escola. Não é pouca coisa, é realmente ambicioso, um desafio a ser encarado e acompanhado em tudo que tem de promissor e incerto.

Assim pensar nas novas possibilidades é promover o conhecimento atual de nossa sociedade. É preciso pensar na educação desses corpos infantis, pensar a educação de baixo para cima, dar início ainda na Educação Infantil. Nesse sentido enfatizamos o olhar para os corpos acima de tudo, e primeiramente sem enxergar a distinção dos gêneros. Para nós professores/as cabe abrir os olhos para essa educação que enxerga a criança em suas minúcias, sem ainda ter se aprimorado dos processor culturais e materiais.

\section{VISIBILIDADE DO OUTRO LADO DO MURO, PENSANDO EM UMA PEDAGOGIA QUEER...}

Ao jogar e brincar com esses códigos culturais que marcam os gêneros, ao exagerá-los e exaltá-los, leva a perceber sua não naturalidade. Sua figura estranha e insólita ajuda a lembrar que as formas como nos apresentamos como sujeitos, são sempre, formas inventadas e sancionadas pelas circunstancias culturais em que vivemos. Os corpos considerados 'normais' e 'comuns' são, também, produzidos através de uma série de artefatos, acessórios, gestos e atitudes que uma sociedade arbitrariamente estabeleceu como adequados e legítimos (LOURO, 2013. p, 89).

Para completar o pensamento que inicia essa discussão, apresentamos o que a Prof a Guacira Louro chama de movimento em seu livro "Um Corpo estranho" (2013), questionando como essa teoria não propositiva que remete ao estranho, pode articular-se com a Educação? Quais são os espaços de disciplinamento e quais os espaços de transgressão? Como romper com os binarismos e possibilitar-se a pensar no corpo de uma forma plural? E por fim, como pensar a teoria Queer como uma prática pedagógica?

De maneira inicial, é necessário despir-se do que já está instituído dentro dos muros da escola, abrir mão do que a sociedade espera que seja ensinado e assim propagado de forma disciplinar. Uma prática queer permite então pensar na "ambiguidade, multiplicidade, fluidez das identidades, mas além disso, também sugere novas formas de pensar a cultura, o conhecimento, o poder e a educação" (LOURO, 2013. p. 48-49).

Neste contexto, se faz entender que a pedagogia queer constituída por suas práticas desestabilizadoras, permite pensar no diferente, no excêntrico, no impensável, 
em todos/as aqueles/as que estavam à margem da invisibilidade, de modo geral, fora de um campo de reconhecimento.

Visibilizar a partir dessa prática de desconstrução, permite também questionar, problematizar, contestar as engenharias de produção de corpos normalizados, trazer para si o olhar para estes corpos que por muito tempo deixaram de ser vistos. Vale ressaltar que essa 'maquinaria' como elenca Bujes (2002), em sua tese intitulada 'Infância e Maquinarias', em que apresenta todo processo de sanções de governamento e normatização que se inicia lá na Educação Infantil. Assim antes mesmo que a criança inicie seu processo de ensino e aprendizagem, exercícios de ordenamento sobre seu comportamento, e passa a fazer parte de uma ordem de regulamentação sobre que é aceitável e o que não é.

A intenção de possibilitar uma reflexão sobre estes corpos é permitir pensar nas crianças sem distinção de gênero, observar as formas que estão sendo respaldadas nas práticas e de que maneira este corpo infantil está sendo educado. Permitir reajustar e por em discussão os paradigmas da educação normativa, disciplinar, biologizada e binária. Assim, a "diferença deixaria de estar lá fora, do outro lado, alheia ao sujeito, e seria compreendida como indispensável para a existência do próprio sujeito. [...] deixaria de estar ausente para estar presente, assombrando e desestabilizando o sujeito" (LOURO, 2013. p, 50).

Deixar que a criança se expresse segundo sua vontade seja ela menino ou menina. Não excluir o corpo ou negá-lo para assim eximir-se de qualquer pensamento ou atitude que não seja aceita pela escola e/ou família, mas possibilitar a estas crianças um espaço que ela possa ser ela mesma sem preocupar-se ainda com padrões já estabelecidos, às vezes muito tempo antes de nascerem. Ainda, para Louro (2013, p. 50)

Para uma pedagogia e um currículo queer, não seria suficiente denunciar a negação e o submetimento dos/as homossexuais, e sim desconstruir o processo pelo qual alguns sujeitos se tornam normalizados e outros marginalizados, tornando evidente a heteronormatividade, o quanto é necessária a constante reiteração das normas sociais regulatórias.

Portanto, é necessário se pensar no processo de formação desses corpos, os quais, muitas vezes são deixados de lado, pois procura-se representar somente aquele que é normal, e que não exerce nenhum comportamento que vá contra a normatividade.

Assim refletimos sobre as práticas dos/as professores/as tanto da (EI) Educação Infantil, quanto dos Anos Iniciais (AI), afim de, provocar a pensar nessas pedagogias 
e nesses currículos, que norteiam as atitudes, a formação, a constituição da identidade do quem sou eu? Como minha família me vê? Como devo ser? Quais comportamentos são aceitos? Em contrapartida, ressalto ainda o fazer em relação formação de professores/as. Para tratar dessa transgressão de um currículo e uma prática a qual está sempre focada em manter os padrões normativos, é preciso seguir sem medo das incertezas e dos desafios, possibilitando-se descontruir a visão naturalista empregada ao gênero.

Para Teixeira e Magnabosco $(2010,13)$

a escola é uma instituição que tem por finalidade educar para a cidadania, igualdade e a ampliação dos direitos. Presenciamos muitas escolas reproduzindo práticas sexistas, que, através de normas, formas de avaliação, livros didáticos, currículos, disciplinas etc., não problematizam e/ou não abordam as questões de gênero assim como outras produções discursivas e linguísticas que hierarquizam as diferenças produzindo as desigualdades no ambiente escolar.

Neste viés salientamos a importância de aprofundar o trabalho, no ensino primário, para que a distinção dos gêneros sejam reconhecidas e que tais corpos sejam vistos a partir de suas afirmações e diversidades. Que o corpo constituído de gênero, passe a eximir-se do compromisso padronizado, imposto pela sociedade. Mesmo sabendo que a sociedade ainda é mantida por estas relações, sanções e engenharias, mas sobre tudo, práticas escolares que condizem com a invisibilidade do ser diferente, do outro, do estranho e do marginalizado.

Nas contribuições de Guizzo, Beck, Felipe (2013, p. 41),

[...] cabe referir que provavelmente o pouco conhecimento sobre gênero e sexualidades seja um dos motivos fundamentais pelos quais os profissionais do campo da educação continuam ensinando e regulando, "discretamente" (ás vezes nem tanto!) maneiras mais "adequadas" de meninos e meninas se comportarem. Problematizar e estranhar as formas de lidar com as crianças, especialmente no que se refere ás questões de gênero, talvez se apresente como um começo para que essas questões passem a ser tratadas de forma um pouco diferente e menos preconceituosas.

É relevante, pensar sobre a construção da identidade sexual e de gênero, como uma possibilidade de transformação, na medida em que as crianças possam sobretudo escolher, construir sua identidade. Para Louro (2013, p. 14),

nossos corpos constituem-se na referência que ancora, por fim, a identidade. E, aparentemente, o corpo é inequívoco, evidente por si; em consequência, esperamos que o corpo dite a identidade, sem ambiguidade nem inconstância. Aparentemente se seduz uma identidade de gênero, sexual ou ética de "marcas" biológicas; o processo é, 
no entanto, muito mais complexo, e essa dedução pode ser (e muitas vezes é) equivocada. Os corpos são significados pela cultura e são, a são continuamente, por ela alterados.

Na medida em que se reestrutura nossa sociedade, faz-se necessário trazer para dentro dos espaços educativos, possibilidades que aproximem as crianças desses assuntos, os quais por muitas vezes são vivenciadas por elas mesmas. Transcender, é fazer com que esses corpos infantis, estejam de certa forma preparados para pensar, outras possibilidades.

Ainda assim, no espaço escolar há muitos sentimentos anulados que ao tentar expandir-se, transcender, mas por muitas vezes são resgatados, trazidos novamente às normas na intensão de não se deixar expandir ou transcender a normatização estabelecida no ambiente escolar. Complementamos com as palavras de Teixeira e Magnabosco (2010, p. 37),

\begin{abstract}
se a escola, enquanto um espaço relacional de construção e respeito à diversidade, estabelece relações que constroem mais corpos invisíveis e disciplinados do que corpos liberados, como fica a qualidade de nosso raciocínios, a construção de nossa cognição, a liberdade de nossa imaginação e do movimento de nossos corpos? Como fica a construção de gênero em nossas relações? Será que temos incentivado nossas/os alunas/os a construírem corpos onde a questão do gênero não é mera justaposição a papéis sociais do masculino e feminino e, muito menos, uma redução à constituição biológica da genitália? Teremos nós mesmo, professoras/es e educadoras/es, o saber sobre a constituição histórica do corpo?.
\end{abstract}

Contudo, passamos a perceber então que a escola precisa tornar-se ainda mais, uma lugar de formação e ocupação de novas práticas, repensando assim sua constituição enquanto espaço formador. Assim, a proposta da pedagogia queer requer entender que é por meio das "relações que mantemos com nossas/os educadoras/es, também aprendemos gestos, comportamentos, expressões corporais condizentes com os valores pessoais e pedagógicos, não só da/o educadora/or mas da instituição da qual ela/ele participa" (TEIXEIRA e MAGNABOSCO, 2010. p. 32). Nesse sentido o fazer pedagógico para visibilizar os corpos invisíveis tornará, entretanto, uma pratica transgressora de tudo aquilo que já está estabelecido dentro dos muros da escola.

\title{
DA TEORIA QUEER PARA SALA DE AULA...
}

"Num mundo de fluxo aparentemente constante, onde os pontos fixos estão se movendo ou se dissolvendo, segurando o que nos parece ser mais tangível, a verdade de nossa necessidade e desejos corporais. [...] O corpo é visto como a corte de julgamento final sobre o que somos 
ou o que podemos nos tornar. Por que outra razão estamos tão preocupados em saber se os desejos sexuais, sejam hetero ou homossexuais, são inatos ou adquiridos? Por que outra razão estamos tão preocupados em saber se o comportamento generificado corresponde aos atribuídos/ Apenas porque tudo o mais é tão incerto que precisamos do julgamento que, aparentemente, nossos corpos pronunciam". (WEEKS, 1995. Apud in LOURO, 2013. p. 14).

A fim de, contemplar as discussões apresentadas anteriormente, neste segmento, apresentamos a experiência prática de sala de aula. A qual nos suscitou pensar estes corpos, e a maneira de como, ainda mantemos uma postura de afirmação dessa prática 'normalizadora', mesmo estando atentos/as às necessidades de transgressões.

Nesse entendimento, propomos refletir de qual maneira nossas atitudes didáticas contribuem para a constituição desses corpos invisíveis, ou contribui para a transgressão. Dando a eles/as, noções e espaços, os quais lhes permite ser da maneira foram se constituindo enquanto sujeitos autônomos.

Pensamos que a preocupação em torno desse corpo é uma forma de resistência da sociedade, mas principalmente da família, a qual trás resquícios de valores e caraterísticas fundamentais de um padrão aceitável, ou seja, o sujeito 'normal' heterossexual. O qual, não apresenta-se nas margens, nem tão pouco, está fora do que a sociedade irá reconhecer.

A EI enquanto uma modalidade de ensino primária e inicial na vida escolar da criança carrega em si a chance de apresentar de maneira lúdica e potencializada através de suas práticas, de como a construção do sujeito e a sua liberdade de expressão corporal, serão valorizadas dentro do que ela/e acredita. Nós enquanto professores/as, precisamos pensar nessa urgência da reflexão sobre nossa própria prática, e pensar em como estamos colocando nossos questionamentos sobre o/a outro/a, sobre aquela criança que quer se permitir vivenciar outras oportunidades às quais não sejam aquelas estabelecidas por sua família, escola, religião, sociedade e cultura. Neste viés, esse movimento, nos permitirá realizar um movimento didático de ensino contrário ao da invisibilidade e da reprodução das ações heteronormativas predominantes.

Neste viés, refletir sobre as contribuições das pedagogias Queer, nos provoca, nos toca, no sentido de que é emergente olhar para todo/as, despindo-se de qualquer pensamento normativo, fechado, padronizado. As lutas, discussões, reflexões, movimentos, produções de materiais, e uma grande diversidade de artefatos, vem sendo construídos e apresentados no campo da educação, para que estes estigmas se dissolvam, dando espaço para um outro pensar as constituições dos corpos. 
Ainda assim, as discussões de gênero e sexualidade ao perpassarem o ambiente escolar, ainda provocam incomodações, trazendo atitudes que acabam por resgatar medidas disciplinares que se encarregam de punir ou manter dentro dessa norma heterossexual, as crianças às quais demonstram resistências em seus comportamentos subversivos.

O pensar, e o fazer, sobre a infância queer requer de todos/as nós, uma posição contrária a essa resistência do padrão normativo hegemônico a ser seguido, e jamais contestado. Um misto de atos e atitudes a serem seguidos para não ocorrer o risco da subversão, para que esse corpo não transcenda ao que lhe é permitido fazer e agir dentro do espaço escola.

Que tipo de relação pode ajudar a construir um corpo invisível, ou seja, aquele cuja presença é negada e anulada diante o outro? Você já percebeu como, às vezes, em função da correria do dia a dia, da atenção desfocada, anulamos a presença de um corpo ao nos relacionarmos com ele de modo indiferente? Você já olhou e não viu um aluno? Você já tratou com indiferença aquele/a aluno/a que não correspondeu às expectativas em sala de aula? [...] uma educação muito constritora acaba ensinando os corpos a se invisibilizarem, tamanha a vergonha de aparecerem tal como estão sendo no momento (TEIXEIRA e MAGNABOSCO, 2010. p. 35).

Segundo Preciado (2012, p. 1) as crianças queers são "privadas de qualquer forma de resistência, de qualquer possibilidade de usar seu corpo livre e coletivamente, usar seus órgãos e seus fluidos sexuais". A autora ainda nos prova refletir sobre alguns pontos deste pensamento sobre as crianças que fogem do padrão normativo, como apresenta tais questionamentos:

Quem defende o direito das crianças diferentes? Os direitos do menino que adora se vestir de rosa? Da menina que sonha em se casar com a sua melhor amiga? Os direitos da criança queer, bicha, sapatão, transexual ou transgênero? Quem defende o direito da criança a mudar de gênero, se for da vontade dela? Os direitos das crianças à livre autodeterminação de gênero e de sexualidade? Quem defende os direitos da criança a crescer num mundo sem violência sexual ou de gênero?

Se pensarmos em um padrão normativo de gênero, logo nos remetemos à educação de meninos e meninas, assim a preocupação apenas em educá-los segundo seu sexo biológico, não permitindo a esses corpos pensar sobre outras identidades. A constituição heterossexual sobre o corpo masculino e a maneira com a qual se comporta está totalmente ligada à sua questão de gênero, ao infringir as normas 'legitimas'. No entanto, ao brincar de bonecas, dançar, cozinhar, dentro de um imaginário lúdico, pelos meninos é estar subvertendo o padrão normativo hegemônico. 
As crianças passam a ser tratadas a partir do olhar de invisibilidade de 'anormais'. Neste sentido de reação a uma atitude inesperada, Louro (2012), ressalta que através dessas atitudes, "busca-se enfatizar mais as práticas do que as identidades e questionar os binarismos sobre os quais se assenta o saber e a cultura dominantes" (p. 367).

Segundo Colling (2009, p. 1),

um dos maiores esforços reside na crítica ao que se convencionou chamar de heteronormatividade homofóbica, defendida por aqueles que vêem o modelo heterossexual como o único correto e saudável. Por isso, os primeiros trabalhos dos teóricos queer apontam que este modelo foi construído para normatizar as relações sexuais. Assim, os pesquisadores e ativistas pretendem desconstruir o argumento de que sexualidade segue um curso natural.

Foucault em algumas de suas obras - Segurança, Território, População (1977-1978) (FOUCAULT, 2008a) e Nascimento da Biopolítica (1978-1979) (FOUCAULT, 2008b) -, apresenta diversas análises, as quais nos suscitam pensar sobre o cenário atual educacional e social. A educação ainda marca as infâncias por suas intervenções e mecanismos institucionais de padronização. Foucault (2005) e Bujes (2002), nos remetem a pensar a governamentalidade, e os meios maquinário das engenharias de normatização, a partir do conceito de governo, o qual está imbricado pelos sistemas de racionalidade, poder e normas de conduta. O governo das infâncias na educação escolar, está implicado pelos discursos científicos, políticos, pedagógicos e culturais, os quais acabam por fabricar formas de subjetivação e de controle das condutas desses corpos, na intenção de torna-los dóceis. Conforme Prado Filho (2006, p. 50):

[..] a partir do século XVII surgem variadas formas de governo: no geral, um governo sobre a vida, condução da conduta dos indivíduos, mas apontam para formas mais finas de governo - governo do corpo pelas disciplinas, ou governo disciplinar do corpo; governo pela norma que implica o reconhecimento de si mesmo numa identidade; um governo do olhar, que é quase um império de visibilidade. [...] É esta diversidade de práticas de poder que será colonizada pela forma governo - será governamentalizada - na passagem à modernidade.

No entanto, a governamentalidade vêm a caracterizar novas estratégias de controle das condutas dos corpos/comportamentos infantis. Nesse sentido, a escola precisa estar atenta e informada sobre a nova geração de invade as salas de aula, permitindo-se pensar para quem servem esses padrões? A partir de quem são estabelecidos? 
Furlani (2011) ressalta que, professores/as comprometidos com a proposta da pedagogia queer "devem procurar perturbar, sacudir as formas de se posicionarem perante as dimensões da educação sexual que, tradicionalmente, vêm sendo realizadas no Brasil” (p. 40). Não permitindo que sejam atravessados pelas propostas sociais de conduta, que invadem os muros da escola e que por muitas vezes, acabam por redigir a proposta curricular. Faz-se necessário, sentir-se incomodado/a, preocupados/as com todos esses processos que calam o ser transgressor.

Segundo Britzman (1995 apud FURLANI, 2011, p. 38)

na teoria Queer, a normalidade (o estado normal) é uma ordem conceitual que rejeita imaginar como real a possibilidade do "outro", precisamente porque a produção da diversidade é central para ela própria se autorreconhecer. Na ação pedagógica educacional, estar atento e apontar para essa produção da normalidade permite-nos considerar, de modo simultâneo, "as instáveis relações diferenciais" entre aqueles que transgridem o normal e aqueles que trabalham para ser reconhecidos como normal".

É possível perceber que as infâncias e o ser criança nesta fase servem para “possibilitar entendimentos particulares sobre como se delineiam as relações de força na sociedade, as relações de poder - eficazes, mas invisíveis - que moldam certos modos de ser criança, de viver esta idade e de nela descobrir o mundo" (BUJES, 2002, p. 20). Assim, podemos dizer que "governar as infâncias significa educar as crianças, moldando-lhes a alma que é, ao mesmo tempo, efeito e instrumento de uma anatomopolítica dos e sobre os corpos infantis" (VEIGA-NETO, 2015, p. 55).

Todas essas técnicas, as quais podemos chamar também de estratégias de governamento e normatização, resultaram em disciplinas, as quais, "aplicam-se aos corpos individuais mas também aos corpos sociais: separam, organizam e especializam espaços, especializam e mecanizam atividades; serializam, articulam e acoplam corpos e processos" (PRADO FILHO, 2006, p. 46). As disciplinas investem nos corpos, a fim de garantir corpos produtivos e normalizados, produzidos a partir de uma "complexa rede de micropoderes disciplinares que atuavam de maneira a gerir e administrar a vida humana, tendo em vista tornar possível a utilização dos corpos e a exploração otimizada de suas capacidades e potencialidades" (DUARTE, 2013, p. 48).

Nesse entendimento as ações pedagógicas pensada para a produção da diversidade, da diferença se faz necessária nesse campo de estudos Queer, possibilitando às crianças a exercerem as mais diversas brincadeiras e atividades sem ser julgadas, possibilitar a trabalhar com as famílias, para que estas também passem 
a atender e a aceitar que meninas e meninos troquem de papéis e se permitem viver outras experiências. A infância do século XXI, diferente, estranha, excêntrica, subversiva, tem seu papel de não aceitar ser mantida no enquadramento padronizado de comportamento.

Enquanto professores/as, sentimos provocados/as por esse estudo, por pensar essa possibilidade das 'Pedagogias Queer', para que na escola as crianças tenham essa possibilidade de subverter-se. Louro (2012, p. 368) nos instiga a pensar que,

não temos que indicar o que fazer concretamente nas salas de aula. Talvez a potencialidade Queer esteja na disposição para a incerteza, para o improviso e para o movimento. Há que arriscar, experimentar, ousar. Se não tiver outro jeito, vamos lidar, quem sabe, com certezas provisórias, mas, sempre que possível valeria perturbar essas certezas e colocar a questão: "e se...?".

Cabe problematizar, o que está posto, problematizar a norma, os padrões hegemônicos instituídos e institucionalizados. Padrões que enquadram todas as crianças, sem ao menos pensar em sua sexualidade, apenas em seu sexo biológico. Segundo Caetano (2013, p. 62-63),

o currículo que se realiza nas práticas cotidianas não é um elemento neutro, de transmissão desinteressada do conhecimento, mas influenciado por interesses que são eleitos pela escola e/ou pelo sistema educativo. Inúmeros conteúdos curriculares são cotidianamente transmitidos nas escolas, com possíveis efeitos em exclusões e discriminações, que têm sido causa de expressivos sofrimentos decorrentes da demarcação da supremacia masculina e da heteronormatividade. [...] O que propomos é, sobretudo, o avanço epistemológico, político e objetivo, que efetivamente destitua a lógica binária e seus efeitos. Confirmamos, então, que é necessário questionar os processos pelos quais uma forma de sexualidade (a heterossexual) e um governo de gênero (o masculino) acabaram por se tornar a norma e passaram a ser entendidos como "naturais".

Caetano (2013), salienta que não basta somente reivindicá-los, nem tampouco os materiais e os livros didáticos, mas sim tentar compreender o status hegemônicos e as políticas locais. Para prosseguir com o pensamento de diferença que está presente nas escolas, problematizando estes materiais e também o currículo. É na primeira inserção da criança com a escola, que precisa iniciar-se o trabalho sobre o questionamento dessas técnicas e disciplinas de normatização. A fim de, mudar esse cenário de discriminação e de invisibilidade da criança que subverte as normas institucionais idealizadas.

É possível pensar que a escola da modernidade a partir de uma série de saberes sobre as infâncias, sobre as/os professoras/es, sobre os conteúdos, sobre os processos 
de ensino e a aprendizagem, estabelece um padrão desejável, "funcionando assim como uma máquina de governamentalização. [...] Isso faz da escola um lugar privilegiado para se observar, por exemplo, tanto as transformações que já acontecem quanto as que ainda estão acontecendo na lógica social” (VEIGA-NETO, 2001, p. 109). Dornelles (2005, p. 101) ressalta que,

estas infâncias que estão sendo construídas causam medo e até desconforto, especialmente no que tange às manifestações de sexualidade na mais tenra idade. Porém "é nesta trama discursiva e paradoxal que vivem e convivem as diferentes infâncias fabricadas pela sociedade globalizada com as quais temos 'medo' de lidar, talvez por ainda não se terem produzido saberes e poderes suficientes para controlá-las e governá-las”.

Sobre o olhar que dedicamos esta escrita, percebemos a possibilidade de uma educação pensada a partir das contribuições do GEERGE e as provocações de Louro (2012), sobre as pedagogias queer, e as estratégias de transcender e subverter os padrões impostos como únicos e normativos.

Visamos, então, problematizar que é possível que as verdades instauradas pela sociedade, sejam repensadas e refletidas a partir das discussões e estratégias de possibilidades da construção do sujeito. Desconstruindo estigmas instaurados acerca das diversidades sexuais e de gênero, tornando o espaço da escola um espaço possível e potente para se fazer valer uma educação de visibilidade dos corpos invisíveis.

\section{ENXERGANDO O QUE ESTAVA INVISÍVEL, DISCUTINDO O QUE ESTAVA}

IMPOSTO: para continuar praticando a pedagogia queer...

Essa visibilidade é fundamental para subverter a dicotomia sexo/gênero heteronormativa, mostrando uma infinidade de estranhos arranjos de identidade e de estilos Queer, o que possibilita uma desestabilização do entendimento de que as configurações de gênero e do desejo são únicas ou fixas" Furlani (2011, p. 37).

O investimento desta escrita teve como intencionalidade apresentar possibilidades de discutir as estratégias de normatização dos corpos invisíveis dentro do espaço escolar, assim como, promover a reflexão a cerca das estratégias de transgressão a partir das pedagogias queers. Nossa provocação foi suscitar ao professor/as pensar nas inquietações e incertezas, discussões e entendimentos, que se faz necessário dentro do espaço escolar e fora dele.

O movimento inicial de construção desta escrita deu-se a partir da Disciplina: Corpos, Subjetividade e Docência (2014) - do curso de Mestrado do Programa de Pós 
Graduação da Universidade Federal de Rio Grande. PPGedu/FURG. Com a provocação de pensar a construção dos corpos, a partir das técnicas de normatização e de transgressão. No decorrer, o referencial teórico foi sendo construindo com a colaboração da Disciplina: Gênero, sexualidade e a produção da diferença (2015), também ofertada através da grade curricular do PPGedu. Através dos diálogos estabelecidos sobre a escola, os padrões normativos, e os estudos Queer, pensando sobre este aspectos direcionados à infância.

Contudo, entendemos ser necessário o diálogo, entre escola e o constituir-se sujeito dentro dela, possibilitando as diversas formas de se constituir um ser individual em sua multiplicidade transgressiva ou não.

Assim entendo a necessidade do olhar sobre a formação do sujeito, pensando nas possibilidades de se trabalhar as práticas sem dar ênfase aos modelos normativos de comportamento destinados a meninos e meninas.

Contudo, concluímos que a caminhada que se tornou necessária em 1090 com a criação do GEERGE, segue com foça até hoje, mantendo visível as discussões a cerca dos gêneros, sexualidades, corpos, etnias e das pedagogias que refletem sobre os padrões normativos. Temos o entendimento que esse movimento de reflexão não se esgota aqui, mas esperamos que nosso investimento sobre essa temática, tenha possibilitado consideráveis contribuições na desconstrução das 'normas' estabelecidas sobre gêneros e sexualidades e a promoção dessas discussões na escola e em outros espaços educativos.

\section{REFERÊNCIAS}

BENTO, Berenice. Na escola se aprende que a diferença se faz diferença. Estudos Feministas. Florianópolis, v. 19, n.2, p. 549-559, maio-ago. 2011. Disponível em: http://www.scielo.br/scielo.php?pid=S0104-026X2011000200016\&script=sci_abstract \&tlng $=\mathrm{pt}$

BUJES, Maria Isabel Edelweiss. Infância e Maquinarias. Rio de Janeiro: DP\&A, 2002.

CAETANO, Marcio. Gênero e sexualidade: diálogos e conflitos. In. RANGEL, Mary. A escola diante da diversidade. Rio de Janeiro: Wak Editora, 2013. 35-68.

CAMARGO, Ana Maria Faccioli de. Sexualidade(s) e infância(s): a sexualidade como um tema transversal/ Ana Maria Faccioli de Camargo, Claudia Ribeiro; coordenação Ulisses F. Araújo. - São Paulo: Moderna; Campinas, SP: Editora da Universidade de Campinas, 1999. - (Educação em pauta: Temas Transversais).

COLLING, Leandro. Teoria Queer. 2009. Acessado em 25/07/2014. Disponível em: http://www.cult.ufba.br/maisdefinicoes/TEORIAQUEER.pdf 
DORNELLES, Leni Vieira. Infâncias que nos escapam: da criança na rua à criança cyber. Petrópolis/RJ: Vozes, 2005.

DUARTE, André. Biopolítica e resistência: o legado de Michel Foucault. In: RAGO, Margareth; VEIGA-NETO, Alfredo (Orgs.). Figuras de Foucault. 3 ed. Belo Horizonte: Autêntica, 2013, p. 45-55.

FELIPE, Jane; GUIZZO, Bianca Salazar; BECK, Dinah Quesada (Orgs.). Infâncias, gêneros e sexualidade nas tramas da cultura e da educação. Canoas: ULBRA, 2013, p. 17-27.

FOUCAULT, Michel. Segurança, Território e População: curso dado no Collège de France (1977-1978). São Paulo: Martins Fontes, 2008a.

FOUCAULT, Michel. Nascimento da biopolítica: curso dado no Collège de France (1978-1979). São Paulo: Martins Fontes, 2008b.

FURLANI, Jimena. Educação sexual na sala de aula: relações de gênero, orientação sexual e igualdade étnico-racial numa proposta de respeito às diferenças / Jimena Furlani. - Belo Horizonte: Autêntica Editora, 2011.

GUIZZO, B.Z; BECK, D.Q; FELIPE, J. Infâncias, gênero e sexualidade: articulações possíveis. In: Infâncias, gênero e sexualidade nas tramas da cultura e da educação / (organizadoras) Jane Felipe, Bianca Salazar Guizzo, Dinah Quesada Beck. - Canoas; Ed. ULBRA, 2013.

LOURO, Guacira L. Os Estudos Queer e a Educação no Brasil: articulações, tensões, resistências. Contemporânea - Revista de Sociologia da UFSCar. São Carlos, v. 2, n. 2, jul-dez 2012, pp. 363-369. Acessado em 05/06/2014. Disponível em: http://www.contemporanea.ufscar.br/index.php/contemporanea/article/view/87

LOURO, Guacira Lopes. Gênero, sexualidade e educação: Uma perspectiva pós-estruturalista. Petróplolis, Rio de Janeiro: Vozes, 2013.

MISKOLCI, Richard. Teoria Queer: um aprendizado pelas diferenças/ Richard Miskolci. - 2. Ed. Ver. E ampl., 1. Remp. - Belo Horizonte: Autêntica Editora: UFOP Universidade Federal de Ouro Preto, 2013. - (Cadernos da Diversidade; 6).

PRADO FILHO, Kleber. Michel Foucault: uma história da governamentalidade. Rio de Janeiro: Insular, 2006.

PRECIADO, Beatriz. Quem defende a criança Queer. In: http://artilleriainmanente. blogspot.mx/2013/01/beatriz-preciado-quien-defiende-alnino.html. Tradução de Fernanda Nogueira. Acessado em:01/08/2014 Disponível em: http://www.homorrealidade.com.br/2013/01/artigo-quem-defende-criancaQueer.html

RESENDE, Haroldo de.(Org.). Michel Foucault: o governo da infância. Belo Horizonte: Autêntica, 2015.

TEIXEIRA, Cíntia Maria, MAGNABOSCO, Maria Madalena. A construção do conhecimento: gênero e educação. In: Teixeira, Cíntia Maria. Gênero e Diversidade: formação de educadoras/es / Cíntia Maria Teixeira, Maria Madalena Magnabosco. Belo Horizonte: Autêntica Editora; Ouro Preto, MG: UFOP, 2010. - (Série Cadernos da Diversidade).

VEIGA-NETO, Alfredo. Por que governar a infância? In: RESENDE, Haroldo de (Org.). Michel Foucault: o governo da infância. Belo Horizonte: Autêntica, 2015, p. 49-56.

VEIGA-NETO, Alfredo. Incluir para excluir. In: LARROSA, Jorge; SKLIAR, Carlos (Orgs.). Habitantes de babel: políticas e poéticas da diferença. Belo Horizonte: Autêntica, 2001. 